UMTRI-88-41

\title{
EFFECT OF HEADLAMP AREA ON DISCOMFORT GLARE
}

\author{
Michael Sivak \\ Carole J. Simmons \\ Michael J. Flannagan
}

October 1988 
EFFECT OF HEADLAMP AREA ON DISCOMFORT GLARE

\author{
Michael Sivak \\ Carole J. Simmons \\ Michael J. Flannagan \\ The University of Michigan \\ Transportation Research Institute \\ Ann Arbor, Michigan 48109-2150 \\ U.S.A.
}

Report No. UMTRI $-88-41$

October 1988 
Techaical Repert Decumentation Page

\begin{tabular}{|c|c|}
\hline $\begin{array}{l}\text { 1. Report No. } \\
\text { UMTRI-88-41 }\end{array}$ & 3. Recipient' s Cotalog No. \\
\hline \multirow{3}{*}{$\begin{array}{l}\text { 4. Tirle and subritle } \\
\text { EFFECT OF HEADLAMP AREA ON DISCOMFORT GLARE }\end{array}$} & $\begin{array}{l}\text { 5. Report Date } \\
\text { October } 1988\end{array}$ \\
\hline & $\begin{array}{l}\text { 6. Performing Organization Code } \\
302753\end{array}$ \\
\hline & 8. Performing Orgatizetion Report No. \\
\hline $\begin{array}{l}\text { 7. Author's) } \\
\text { Michael Sivak, Carole J. Simmons, and Michael J. Flannagan }\end{array}$ & UMTRI $-88-41$ \\
\hline \multirow{3}{*}{$\begin{array}{l}\text { 9. Perfoming Orgeni zetion Nome and Addres: } \\
\text { The University of Michigan } \\
\text { Transportation Research Institute } \\
\text { Ann Arbor, Michigan } 48109-2150 \text { U.S.A. }\end{array}$} & 10. Work Unit No. (TRAIS) \\
\hline & 11. Contract or Grant No. \\
\hline & 13. Type of Report and Period Covered \\
\hline \multirow{2}{*}{$\begin{array}{l}\text { 12. Spensoring Apency Heme and Addres: } \\
\text { Industry Affiliation Program for } \\
\text { Human Factors in Transportation Safety }\end{array}$} & \\
\hline & 14. Sponsoring Ageney Code \\
\hline
\end{tabular}

15. Supplementory Notes 1988 the members of the Industry Affiliation Program included: Fisher Guide Division of General Motors, GE Lighting, GTE Products Corp., Ichikoh Industries, Ltd., Koito Manufacturing, Co., Ltd., Stanley Electric Co., Ltd., and Valeo Automotive.

16. Abetract

This laboratory study evaluated the effect of the size of the glare source on discomfort glare. The subjects performed two simultaneous tasks: continuous compensatory tracking, and evaluation of discomfort from glare stimuli presented periodically in the near visual periphery. The glare stimuli were circles of two sizes (approximately 0.3 and $0.6^{\circ}$ in diameter), and five illuminance levels (from 0.03 to 3.1 Lux). Subjects used a 9-point response scale to evaluate discomfort glare. The results indicate that there was a small but statistically significant effect of glare size, with the smaller glare stimuli resulting in more discomfort glare. The mean difference over the range of glare illuminances tested was 0.2 points on the 9-point response scale.

\begin{tabular}{|l|l|l|l|}
\hline 17. Koy Word & 18. Distribution Stotommt \\
driving, glare, discomfort glare, headlamps, \\
headlighting, headlamp area, headlamp size, \\
nighttime, perception, subjective scale
\end{tabular}

Reproduction of comploted poge outhorized 


\section{ACKNOWLEDGEMENTS}

Appreciation is extended to the current members of the Industry Affiliation Program for Human Factors in Transportation Safety for financial support of this research:

Fisher Guide Division of General Motors

GE Lighting

GTE Products Corp.

Ichikoh Industries, Ltd.

Koito Manufacturing Co., Ltd.

Stanley Electric Co., Ltd.

Valeo Automotive

Appreciation is also extended to Michael S. Campbell and Paul L. Olson for their assistance with this research. 
CONTENTS

ACKNOWLEDGEMENTS $\ldots \ldots \ldots \ldots \ldots \ldots \ldots \ldots \ldots \ldots \ldots \ldots \ldots$

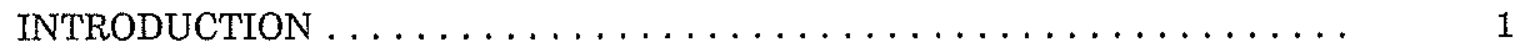

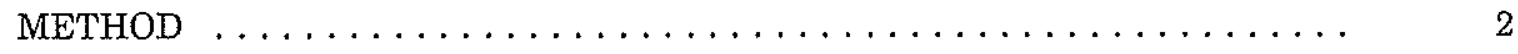

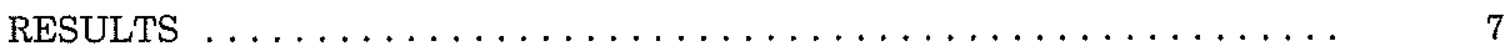

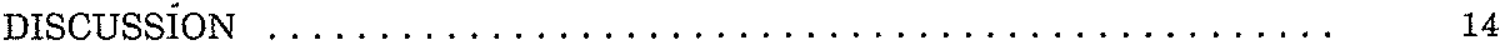




\section{INTRODUCTION}

Recent regulatory actions by the U.S. Department of Transportation have allowed a variety of headlamps to reach the market. While all headlamps still have to meet the FMVSS 108 photometric specifications, the restrictions on size and shape have been considerably relaxed. Consequently, consideration is being given to the production of lamps whose surface area dimensions approach the dimensions of a business card (e.g., 9

$\mathrm{cm} \times 5 \mathrm{~cm}$, or $45 \mathrm{~cm}^{2}$ ). This attests to significant progress in design and manufacturing tolerances in directing the light output only to desirable locations.

Of potential concern, however, is the issue of discomfort glare, since a small-area lamp has a higher luminance (in $\mathrm{cd} / \mathrm{m}^{2}$ ) than a corresponding large-area lamp of identical photometric output. This concern stems from the fact that for an extended light sourcegreater than approximately $1^{\circ}$ of visual angle-several human psychophysical functions are affected more by luminance than by the total amount of light. In a transition zonefor light stimuli between approximately $10^{\prime}$ and $1^{\circ}$-both variables play an important role (e.g., Bartlett, 1965). If this were the case for discomfort glare, the small-area headlamp could create undesirable levels of discomfort glare.

This issue was addressed experimentally by Lindae (1970), by evaluating the borderline between comfort and discomfort for ECE-type 1ow-beam headlamps. On the basis of his results, Lindae concluded that for the ECE-type low-beam headlamps the area is, indeed, of importance in determining discomfort glare. For these lamps he recommended a minimum of $150 \mathrm{~cm}^{2}$ for avoiding discomfort glare.

The present study further evaluated the effect of lamp area on discomfort glare, using a relatively homogeneous light source and a 9-point discomfort-glare rating scale. By using a relatively homogeneous light source as a glare stimulus, the generalizability of the findings is greater than by using a lamp with a specific beam pattern. Additionally, the response scale (i.e., the dependent variable) of choice in the area of vehicle glare is currently a 9-point subjective scale (de Boer, 1973), rather than determination of the borderline between comfort and discomfort (Sivak and Olson, 1988).

To the extent that different parts of a headlamp lens contribute different amounts of light towards a given point in space, the effective (perceived) size of a headlamp (from that point in space) is of potential relevance. It is possible that for a highly heterogeneous headlamp the effective size is smaller than its surface area. Once the relation between the area of a homogeneous glare source and discomfort glare is established, the effective size of non-homogeneous glare sources should therefore also be evaluated. 


\section{METHOD}

\section{Tasks}

The subjects were asked to perform two simultaneous tasks. The primary task was evaluating discomfort glare for stimuli that appeared periodically in the near visual periphery. The secondary, loading task involved continuous compensatory tracking.

\section{Equipment}

A schematic diagram of the experimental set-up is shown in Figure 1. The subject sat at one end of the laboratory in a mock-up of a 1985 Chrysler Laser. The glare source was located $15.25 \mathrm{~m}$ from the subject's eyes, directly in front of the subject. The distance from the center of the glare source to the floor was $88 \mathrm{~cm}$.

The glare source consisted of light from a random-access slide projector which was diffused through a sheet of mylar and a Fresnel lens. On the light-exiting side of the Fresnel lens was a sliding opaque panel with two circular holes $-7.6 \mathrm{~cm}$ and $15.2 \mathrm{~cm}$ in diameter. By sliding this panel back and forth, the experimenter controlled the size of the glare source. Total illuminance reaching the eyes of the subject for the two sizes was equated by an attenuating neutral density filter attached to the larger (i.e., $15.2 \mathrm{~cm}$ ) hole. A set of slides containing neutral density filters provided five levels of total illuminance. Presentation time ( 2 seconds) was controlled by a shutter on the slide projector lens.

The secondary tracking task consisted of a simulated road scene presented on a $48.3-\mathrm{cm}$ television monitor. The road scene was generated by a Commodore- 64 computer. Deviations of the road's center were based upon a 100-point sinusoidal sequence which repeated about every minute. However, since the subject was kept busy with two tasks, to the subject the road appeared to be curving in an unpredictable manner. The subject's task was to keep the road centered on the screen by use of a steering wheel. The television monitor was located $6.1 \mathrm{~m}$ from the subject's eyes, and just to the right of the glare source (see Figure 2). The visual angle from the center of the monitor to the center of the glare source was $3.6^{\circ}$.

A chart of the glare-rating scale was posted in large $1.25-\mathrm{cm}$ letters on a black background, at a distance of $4.7 \mathrm{~m}$ from the subject. The chart was offset so that it appeared just to the right of the television monitor (see Figure 2).

Background luminance of $0.034 \mathrm{~cd} / \mathrm{m}^{2}$ was provided by two small $60 \mathrm{~W}$ lamps. (The luminance readings were taken at two locations: to the left of the glare source and on the bottom part of the response-scale panel.) 
T.V. monitor (tracking task display)

Panel with the response scale
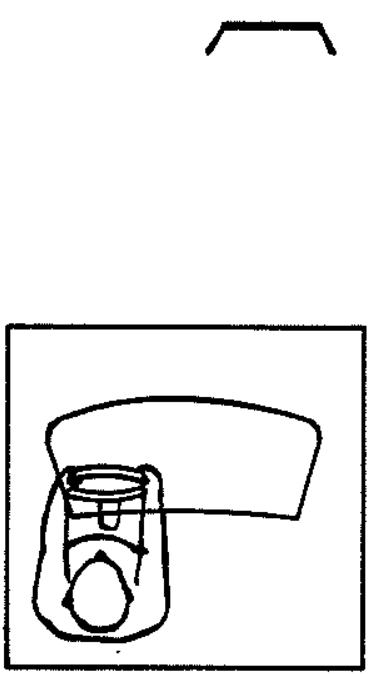

Figure 1. A schematic diagram of the experimental set-up. 


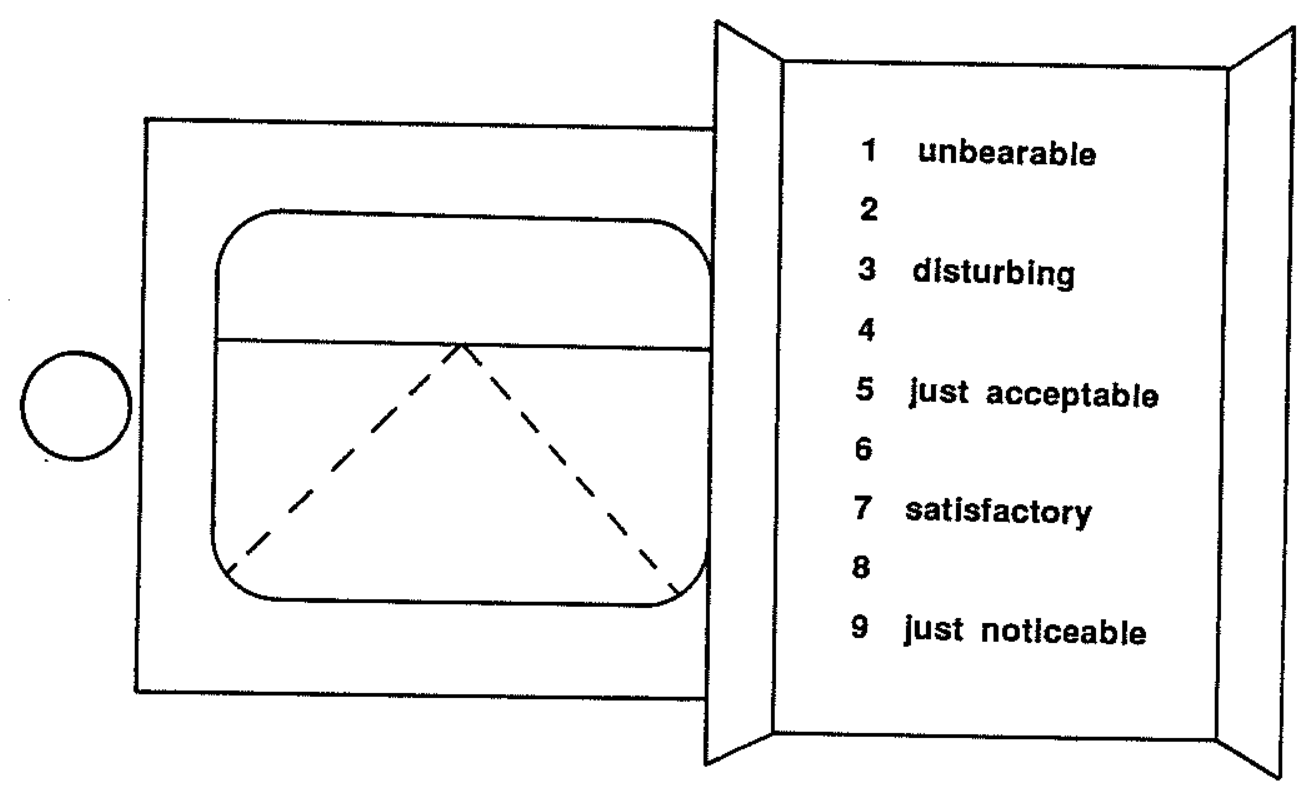

Figure 2. A schematic diagram of the subject's view. 


\section{Response scale}

Subjects were asked to use a 9-point scale (de Boer, 1973) in their assessment of discomfort glare. This scale has qualifiers for only odd points:

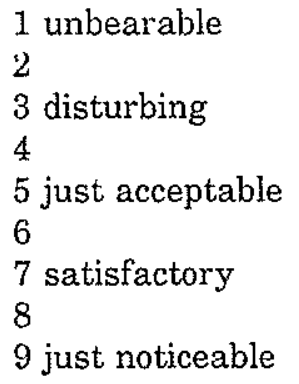

\section{Glare stimuli}

A total of 10 glare stimuli (2 glare sizes $\times 5$ glare illuminance levels) were used. The two glare sizes were 7.6 and $15.2 \mathrm{~cm}$ (in diameter), 45.4 and $181.5 \mathrm{~cm}^{2}$ (in area), or 0.3 and $0.6^{\circ}$ (in visual angle). The five illuminance levels were $0.031,0.097,0.295$, 0.964 , and $3.105 \mathrm{Lux}$-selected in an attempt to utilize most of the 9-point response scale (Schmidt-Clausen and Bindels, 1974; Olson and Sivak, 1984). These values are averages of daily calibrations for large and small stimuli, which were always within $2 \%$ of each other. (In no case did the calibration indicate larger values for the small stimuli.)

Both the large and the small stimuli were perceptually homogeneous. The degree of non-homogeneity was evaluated by measuring the luminance using a Prichard Photometer. For the large stimulus $\left(0.6^{\circ}\right)$ the aperture was set at $0.2^{\circ}$, while for the small stimulus $\left(0.3^{\circ}\right)$ at $0.1^{\circ}$. This arrangement allowed, for each stimulus, three luminance measurements in the horizontal cross-section and three in the vertical cross-section. The obtained readings in the horizontal cross-section were highly homogeneous, with only a $2 \%$ difference between the highest and lowest logarithm of luminance for both the large and the small stimulus. The corresponding differences in the vertical cross-sections were greater, but still acceptable ( $7 \%$ for the small stimulus, and $10 \%$ for the large stimulus).

\section{Subjects}

Sixteen subjects, eight males and eight females, participated in this study. Their ages ranged from 18 to 25 . Subjects were paid for their participation. 


\section{Procedure}

Subjects were tested individually. Each subject was first given several minutes of practice on the tracking task. The glare-assessment task was then explained to the subject. Subjects were told that while doing the tracking task, they would also periodically see brief ( 2 second) flashes of light from the far end of the laboratory. They should continue to watch the driving task, and not look directly at the light. After each light went off, they should refer to the response chart to select the appropriate scale number to describe the discomfort they experienced from the glare of that flash.

Each subject received a set of twenty practice trials, which included two presentations of each of the ten glare stimuli. The responses to these practice trials were checked by the experimenter, to connirm that the subject was using the scale correctly (i.e., assigning generally lower numbers to brighter glare stimuli).

Each subject was given 100 experimental trials, consisting of ten replications of each of the ten glare stimuli. The inter-stimulus interval was approximately 10 seconds. One of two randomly-ordered trial sequences was used with each subject.

A short break was given after the first 50 trials. The test session took about 45 minutes per' subject. 


\section{RESULTS}

The first analysis to be performed was an analysis of variance, with glare illuminance and glare size as factors. As expected, the effect of glare illuminance was statistically significant, $F(4,60)=331.14, p<0.001$. Mean glare ratings for each level of illuminance, collapsed across the two glare sizes, are listed in Table 1.

TABLE 1

Mean glare ratings by level of glare illuminance.

\begin{tabular}{c|c}
\hline $\begin{array}{c}\text { Glare illuminance } \\
\text { (Lux) }\end{array}$ & Mean glare rating \\
\hline 0.031 & 7.37 \\
0.097 & 6.16 \\
0.295 & 5.02 \\
0.964 & 3.61 \\
3.105 & 2.23 \\
\hline
\end{tabular}

The main effect of size of glare source was also statistically significant, $F(1,15)=$ $4.82, p<.05$. Mean glare ratings for the two glare sizes, collapsed across levels of glare illuminance, were 4.78 (for small) and 4.98 (for large). Figure 3 presents the mean glare ratings by glare size and glare illuminance. The interaction of glare size and glare illuminance was not significant, $F(4,60)=1.01, p>.05$.

As the next step, a mean glare-rating difference for large vs. small stimuli was computed for each of the 16 individual subjects (see Table 2). Of these 16 difference scores, 11 were in the sarne direction as the main effect of size in the previous analysis of variance (i.e., 11 subjects gave lower mean glare ratings for the small as opposed to large stimuli). When these difference scores were examined by the sex of the subject, it was found that all eight males, but only three of the eight females, gave lower mean glare ratings for small stimuli (see Table 2). To statistically evaluate this pattern, a second analysis of variance was performed, with sex as an additional factor. As in the first analysis of variance, both glare illuminance $(F(4,56)=315.72, p<.001)$ and glare size $(F(1,14)=6.64, p<.05)$ were significant. The main effect of sex was not statistically 


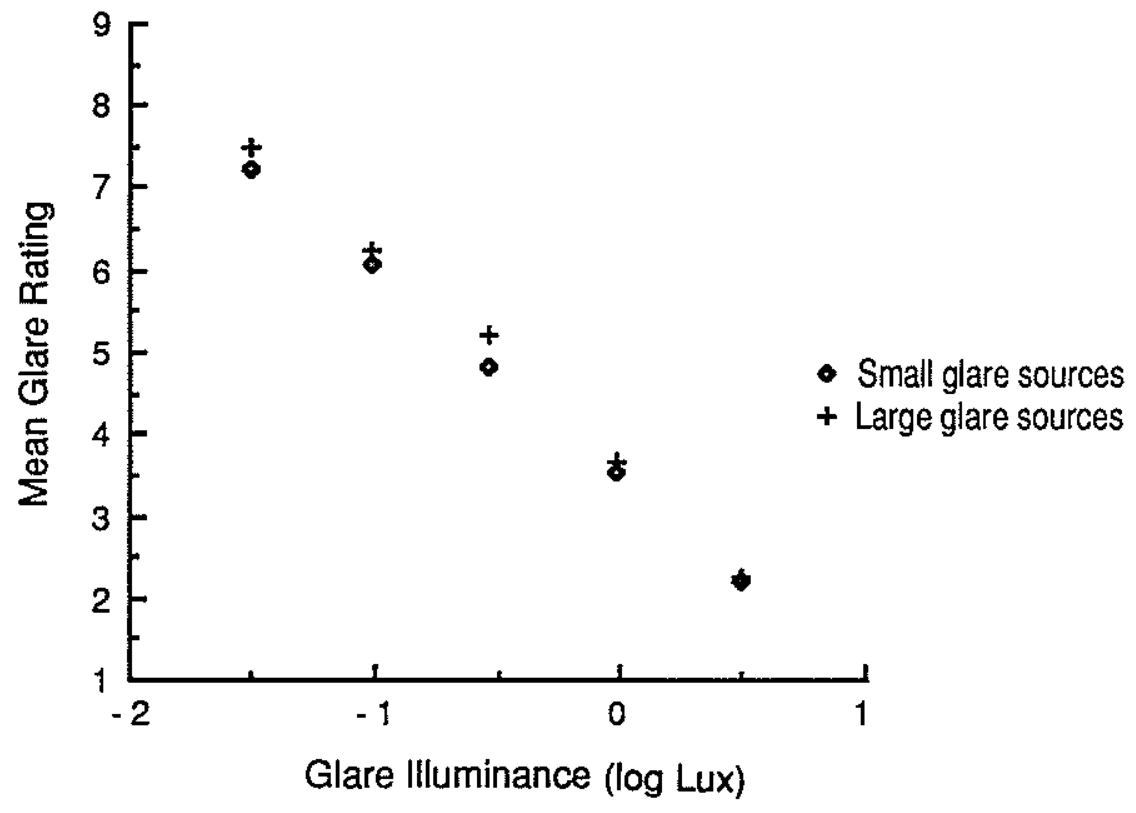

Figure 3. Mean glare ratings by glare size and glare illuminance. 
significant, $F(1,14)=3.54, p>.05$, but the interaction of glare size and sex was statistically significant, $F(1,14)=6.64, p<.05$. Finally, double interactions of glare illuminance and glare size, and glare illuminance and sex, as well as the triple interaction (glare illuminance $\times$ glare size $\times$ sex) were not statistically significant.

The third and final analysis of variance investigated the effects of replications and subjects. The factors in this analysis were glare size, glare illuminance, sex, replications, and subjects. The main effect of replications was not statistically significant, $F(9,126)<$ 1. The effect of subjects was statistically significant, $F(14,126)=25.3, p<.001$.

In the next analyses, least-square regressions of glare ratings on glare illuminance were performed. Because of the main effect of glare size in the analyses of variance, separate regressions were run for large and small stimuli. The resulting equations were as follows:

$$
\begin{aligned}
& y=3.6328-2.6122 x \text { (for large glare sources) } \\
& y=3.4806-2.5195 x \text { (for small glare sources) }
\end{aligned}
$$

where $y$ represents the glare-scale rating, and $x$ is in units of logLux. The regression lines and corresponding data are plotted in Figures 4 and 5. In both cases, the regressions accounted for virtually all of the variance.

These regression equations were used to calculate the predicted glare-scale ratings by glare size for selected values of glare illuminance. The results of these calculations are presented in Table 3. Analogously, these same regression equations were used to derive the glare illuminance levels required to produce a particular glare-scale rating by glare size (see Table 4). 
TABLE 2

Mean glare-rating difference for large vs. small glare stimuli by individual subjects.

(A positive entry in column 3 indicates that the glare rating was higher for the large than for the small glare stimuli.)

\begin{tabular}{|c|c|c|}
\hline Subject & Sex & $\begin{array}{l}\text { Mean difference } \\
\text { in glare ratings }\end{array}$ \\
\hline 1 & Female & -0.20 \\
\hline 2 & Female & 0.36 \\
\hline 3 & Female & -0.08 \\
\hline 4 & Female & 0.30 \\
\hline 5 & Male & 0.32 \\
\hline 6 & Male & 1.18 \\
\hline 7 & Male & 0.06 \\
\hline 8 & Male & 0.14 \\
\hline 9 & Female & -0.12 \\
\hline 10 & Female & -0.24 \\
\hline 11 & Male & 0.48 \\
\hline 12 & Male & 0.14 \\
\hline 13 & Male & 0.70 \\
\hline 14 & Male & 0.18 \\
\hline 15 & Female & 0.02 \\
\hline 16 & Female & -0.04 \\
\hline Mean & & 0.20 \\
\hline
\end{tabular}




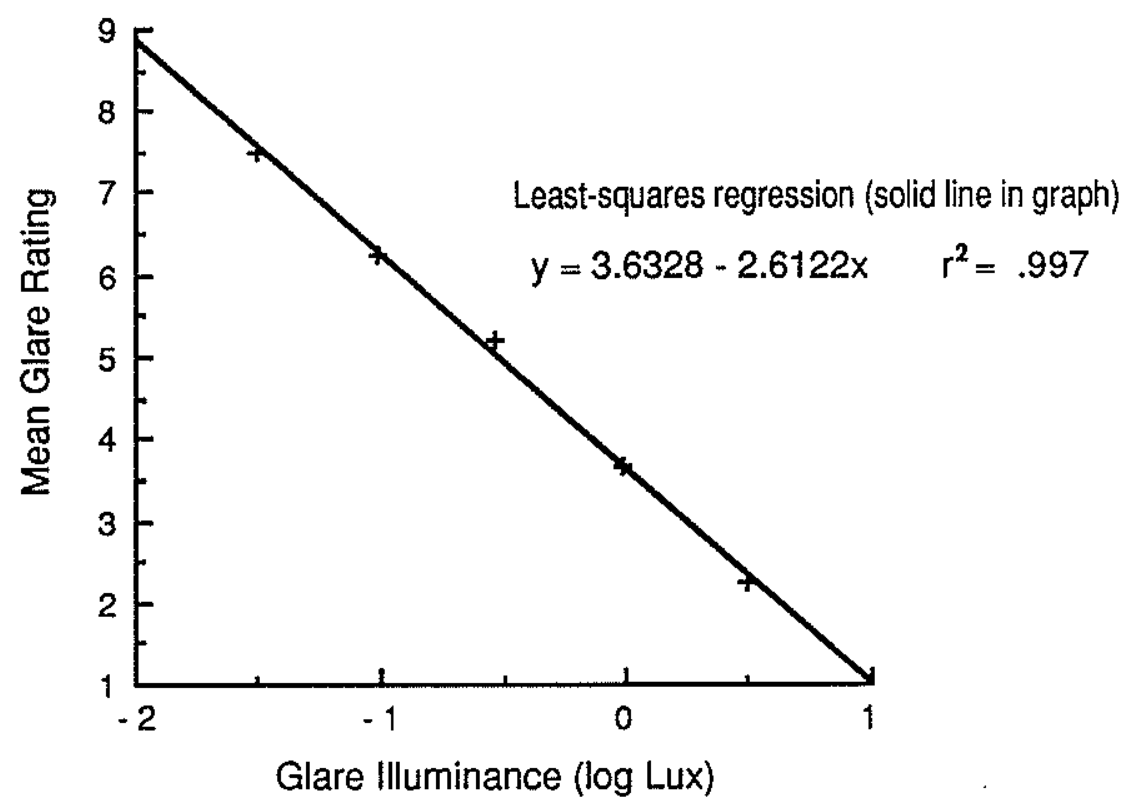

Figure 4. Mean glare ratings by glare illuminance for the large glare sources.

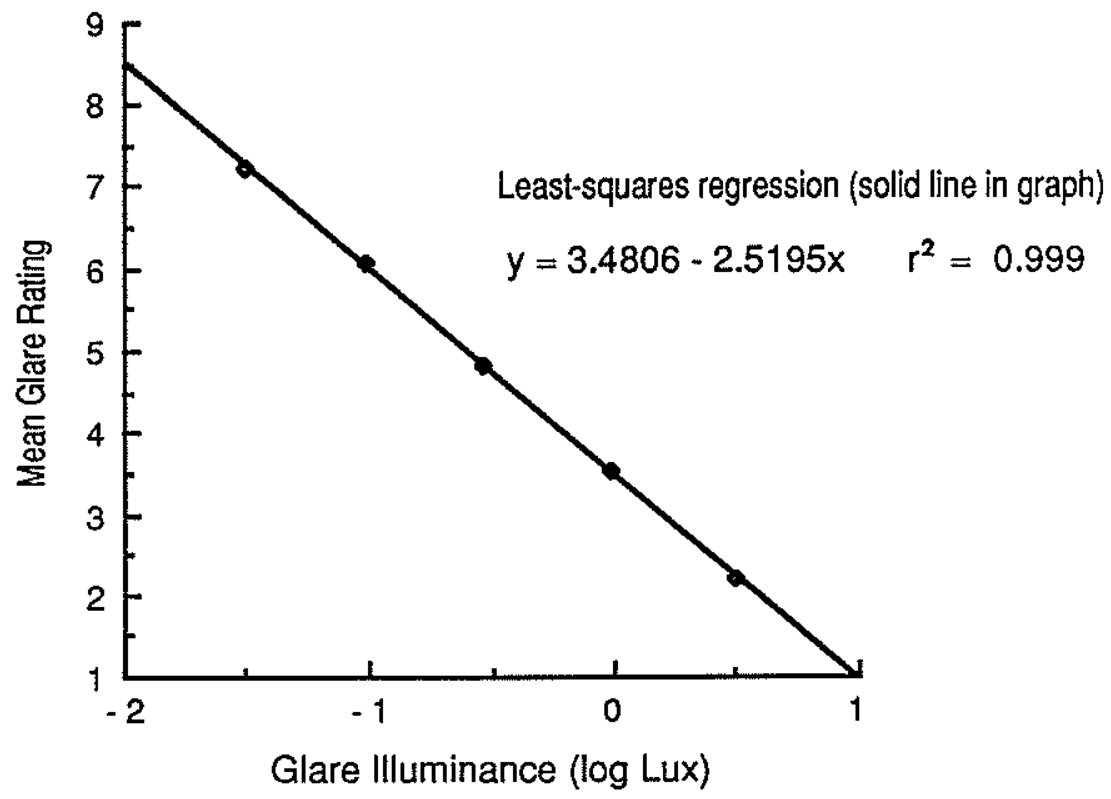

Figure 5. Mean glare ratings by glare illuminance for the small glare sources. 
TABLE 3

Predicted glare ratings by glare size for a range of illuminance values.

(Computed from the regression equations.)

\begin{tabular}{c|c|c}
\hline \multirow{2}{*}{$\begin{array}{c}\text { Glare illuminance } \\
\text { (Lux) }\end{array}$} & \multicolumn{2}{|c}{ Predicted glare rating } \\
\cline { 2 - 3 } 0.10 & 6.24 & Small glare source \\
0.20 & 5.46 & 6.00 \\
0.30 & 5.00 & 5.24 \\
0.40 & 4.67 & 4.80 \\
0.50 & 4.42 & 4.48 \\
0.75 & 3.96 & 4.24 \\
1.00 & 3.63 & 3.80 \\
1.25 & 3.38 & 3.48 \\
1.50 & 3.17 & 3.24 \\
\hline
\end{tabular}


TABLE 4

Required glare illuminance to produce given glare-scale rating by glare size.

(Computed from the regression equations.)

\begin{tabular}{c|c|c}
\hline \multirow{2}{*}{ Glare rating } & \multicolumn{2}{|c}{ Required glare illuminance (Lux) } \\
\cline { 2 - 3 } 1 & Large glare size & Small glare size \\
\hline 2 & 10.183 & 9.651 \\
3 & 4.218 & 3.870 \\
4 & 1.747 & 1.552 \\
5 & 0.723 & 0.622 \\
6 & 0.300 & 0.249 \\
7 & 0.124 & 0.100 \\
8 & 0.051 & 0.040 \\
9 & 0.021 & 0.016 \\
\hline
\end{tabular}




\section{DISCUSSION}

\section{Effect of glare illuminance}

As expected, for a given glare size, the glare rating was a linear function of the logarithm of glare illuminance. For each glare size, the regressions accounted for virtually all of the variance in glare ratings. This finding suggests that subjects were using the response scale not as an ordinal, but as an interval scale-a highly desirable property of a subjective scale.

\section{Effect of glare size}

The main goal of this research was to evaluate the hypothesis that a decrease in headlamp size leads to an increase in discomfort glare. Toward this goal, this study evaluated discomfort glare for relatively homogeneous circular glare sources of two different sizes $\left(0.3\right.$ and $0.6^{\circ}$ in diameter) and a range of glare illuminances (from 0.031 to 3.105 Lux). The results indicate that, indeed, the effect of glare size was statistically significant, and in the expected direction.

The statistical significance of the main effect of glare size needs to be viewed in relation to the fact that there was a significant interaction of glare size and the sex of the subject. Specifically, the effect of size was entirely the result of the effect for males. This finding is difficult to interpret from physiological or psychological points of view. Consequently, it is likely that this is only a spurious finding. Nevertheless, the possibility of a true sex difference cannot be excluded, and future research should address this issue more extensively.

Let us assume that the main effect of glare size is real and the interaction of glare size and sex is spurious. Is the size of the obtained effect of practical consequence? The mean difference in the glare ratings (averaged across all glare illuminance levels) is 0.2 points on a 9-point response scale. This difference varies with glare illuminance. Specifically, the mean difference in glare ratings increases as the glare illuminance decreases. For example, the predicted glare rating for $1 \mathrm{Lux}$ is 3.63 for the large glare source, and 3.48 for the small glare source. The corresponding glare ratings are 5.00 and 4.8 for $0.3 \mathrm{Lux}$, and 6.24 and 6.00 for $0.1 \mathrm{Lux}$. Another way of quantifyirg the effect is to state that to obtain a glare rating of 4 in the present situation, the glare illuminance has to be $0.72 \mathrm{Lux}$ for the large glare source and $0.62 \mathrm{Lux}$ for the small glare source. The obtained differences are not large, especially in comparison with glare effects as a function of headlamp aim (Bhise, Matle, and Hoffmeister, 1984). Nevertheless, the obtained glare- 
size effect is of potential importance, since it is additive to the effects of many other variables, including aim, mounting height, and dirt (through light scatter). 


\section{REFERENCES}

Bartlett, N.R. (1965). Thresholds as dependent on some energy relations and characteristics of the subject. In C.H. Graham (ed.), Vision and visual perception. New York: Wiley.

Bhise, V.D., Matle, C.C., and Hoffmeister, D.H. (1984). Chess Model application in headlamp systems evaluation (SAE Technical Paper \#840046). Warrendale, Pennsylvania: Society of Automotive Engineers.

de Boer, J.B. (1973). Quality criteria for the passing beam of the motorcar headlights. Paper presented at the GTB (Groupe de Travail de mixte de Bruxelles) meeting, Walldorf, West Germany.

Lindae, G. (1970). Optimum size of headlamps for the European lower beam (SAE Technical Paper \#700390). Warrendale, Pennsylvania: Society of Automotive Engineers.

Olson, P.L. and Sivak, M. (1984). Discomfort glare from automobile headlights. Journal of the Illuminating Engineering Society, 13, 296-303.

Schmidt-Clausen, H.-J. and Bindels, J.T.H. (1974). Assessment of discomfort glare in motor vehicle lighting. Lighting Research and Technology, 6, 79-88.

Sivak, M. and Olson, P.L. (1988). Toward the development of a field methodology for evaluating discomfort glare from automobile headlamps. Journal of Safety Research, $19,135-143$. 